\title{
Effect of Dimethoate on Object Recognition Memory in Wistar Rats and Essay of Treatment with Nettle
}

\author{
Majda Samih ${ }^{*}$, Pacôme Kouadio N'Go², Sabah Belaaouja1', Amina Ouazzani Touhami³, \\ Ahmed Omar Touhami Ahami ${ }^{1}$
}

\footnotetext{
${ }^{1}$ Unit of Clinic and Cognitive Neuroscience, Laboratory of Biology and Health, Department of Biology, Faculty of Sciences, Ibn Tofail University, Kenitra, Morocco

${ }^{2}$ Training and Research Unit of Biology Sciences, Peleforo Gon Coulibaly University, Korhogo, Ivory Coast

${ }^{3}$ Botanical and Plant Protection Unit, Laboratory of Biology and Health, Department of Biology, Faculty of Sciences, Ibn Tofail University, Kenitra, Morocco

Email: *majda1_2000@yahoo.fr
}

How to cite this paper: Samih, M., N'Go, P.K., Belaaouja, S., Touhami, A.O. and Ahami, A.O.T. (2017) Effect of Dimethoate on Object Recognition Memory in Wistar Rats and Essay of Treatment with Nettle. Journal of Behavioral and Brain Science, 7, 425-445.

https://doi.org/10.4236/jbbs.2017.79031

Received: July 29, 2017

Accepted: September 22, 2017

Published: September 25, 2017

Copyright $\odot 2017$ by authors and Scientific Research Publishing Inc. This work is licensed under the Creative Commons Attribution International License (CC BY 4.0).

http://creativecommons.org/licenses/by/4.0/

\begin{abstract}
Pesticides were economically important chemicals in agriculture. Their use has permitted agricultural progress, through the eradication of harmful insect and the fight against vectors of disease. However, several studies question the beneficial effects of organophosphorus compounds, showing that their deregulated use causes various problems of environmental pollution and human health. The present study shows that chronic exposure to a subtoxic dose of dimethoate is likely to affect cognitive and behavioral functions of rats (both males and females). Our results show that exposure to dimethoate affects both short and long-term memory capacities. The short-term memory results are more pronounced. Treatment with nettle extract allowed a significant improvement in cognitive and behavioral performance of the rats after their exposure to dimethoate.
\end{abstract}

\section{Keywords}

Dimethoate, Dioic Nettle, Acetylcholinesterase, Chelation, Memory

\section{Introduction}

It was in the 1940s that the first synthetic pesticides appeared on the market with very positive results in increasing agricultural yields. Twenty years later, the first accusations of harm to people's health and the environment were heard [1].

The debate about the risks and benefits of chemical control has since been ex- 
tended and a great deal of research has been carried out to better understand the impact of pesticides on the environment.

The mechanism of acute neurotoxic action of Dimethoate is typically cholinergic. It involves inhibition of Acetylcholinesterase (AChE) of neuronal tissue through its active metabolic form; Omethoate which is 10 times more toxic than dimethoate (WHO, 2003).

Omethoate rapidly binds to the hydroxyl group of the active site of $\mathrm{AChE}$, and undergoes a double displacement reaction involving the hydroxyl-serum and dimethylphosphoryl groups of AChE. Thus, phosphorylated AChE is stable and irreversible.

Inhibition of $\mathrm{AChE}$ causes an accumulation of acetylcholine released in the synaptic cleft upon nerve stimulation, leading to hyperstimulation of the nicotinic and muscarinic receptors. Consequently, the passage of nerve information is disrupted [2]. In addition, oxidative stress caused by lipid peroxidation and promoted by dimethoate is considered to be a second mechanism of toxicity of this organophosphorus [3] [4].

In this study, we will highlight the effect of sub-chronic intoxication by dimethoate on short-term and long-term memory. The poisoning took place on male and female Wistar rats. These intoxicated rats will undergo a trial of treatment by phytochelation. Extract of a medicinal plant, nettle, was obtained by decoction.

Chelation therapy has started as a branch of medicine to remove heavy metals and other toxins from the body by introducing powerful chemical agents that associate with toxins and are then excreted in the urine.

From the point of view of a medical use, several clinical trials carried out in this context confirmed these pharmacological properties in humans.

Urtica dioica L., is a ubiquitous plant of the Urticaceae family, renowned for its unpleasant irritating effects, the nettle is actually rich in vitamins, minerals and numerous medicinal virtues [5]. Over the last few decades, several studies have focused on the pharmacological implications and on the analysis of the chemical composition of the plant. Although all its potentialities have yet to be realized, numerous studies have strengthened its claims in traditional medicine. [6].

Indeed, put into practice in vitro and in vivo in animals, these studies have proved that this plant possesses numerous pharmacological properties in terms of antiproliferative, anti-inflammatory, antioxidant, analgesic, antiulcer, immunostimulating, anti-Infectious, anti-hypertensive and protective against cardiovascular disease. In addition, and in view of its richness in protein, minerals and vitamins, nettle provides a proven nutritional interest. In terms of toxicology, nettle remains innocuous and significant doses, administered orally to humans, showed no side effects.

Nettle extracts have a neutralizing role for reactive oxygen species (ERO). Their anti-free radical activity, with respect to the superoxide anion $\mathrm{O}^{\circ}$, the 
hydroxyl radical $\mathrm{OH}^{\circ}$ and the nitric oxide radical $\mathrm{NO}^{\circ}$, was determined by spectrophotometry. Numerous studies have shown that the methanolic and ethanolic extracts of the leaves have a remarkable antioxidant effect with respect to the 1,1-diphenyl-2-picrylhydrazyl radical (DPPH) [7] [8] [9]. Chelation of ferrous iron was evaluated using ferrozine which forms a red chromophore with residual iron (Fe (II)-Ferrozine) having an absorption maximum at $562 \mathrm{~nm}$. The absorbances obtained show that nettle has an important chelating activity with respect to the ferrous ion [10]. Another study, carried out on rats treated with tetrachloromethane $(\mathrm{CCl} 4)$, showed that nettle decreased lipid peroxidation and increased the activity of the antioxidant defense system thus playing a protective role against hepatotoxicity. This antioxidant activity is essentially correlated with the content of phenolic compounds [7] [11].

Nettle is very rich in polyphenols and is located in different parts of plants according to the plant species and the polyphenolic group considered. These compounds group together a multitude of molecules and represent one of the most important groups present in the plant kingdom. Although they are very diversified, they all have in common the presence of one or more benzene rings carrying one or more hydroxyl functions. Polyphenols are divided into several categories, including flavonoids [SFA, 2005].

Flavonoids act mainly as primary antioxidants, stabilizing peroxide radicals, but they can also deactivate reactive oxygen species, inhibit lipoxygenase or chelate metals [12].

Flavonoids are in vitro enzyme inhibitors of: histidine decarboxylase (by queretol and naringenin), elastase, hyaluronidase (by flavones and proanthocyanidols) and catechol-O-methyltransferase.

\section{Material and Methods}

\subsection{Animals Studied and Condition of Breeding}

The animals used in this study are wistar albino rats (male and female), and are obtained from the Faculty of Science animal house. The animals are reared in transparent plastic cages $(32 \times 15 \times 13 \mathrm{~cm})$, covered by a stainless steel grill. The breeding takes place under standard conditions of ventilation, light (cycle of alternation $12 \mathrm{H}$ light/12H darkness), temperature $(21 \pm 2$ degrees $\mathrm{C})$ and relative humidity $(65 \% \pm 15 \%)$. Rats have ad libitum access to fresh water and secalin-based food (SNV, Temara, Morocco).

\subsection{Treatment of Animals}

\subsubsection{Chronic Toxicity to Dimethoate}

In the adult stage, $120 \mathrm{Wistar}$ rats aged 3 months of average weight ( $160 \pm 40 \mathrm{~g})$ are divided into two groups according to sex, 60 males and 60 females. Since the lethal dose of oral dimethoate was $300 \mathrm{mg} / \mathrm{kg}$ bw in rats [4] [13], we performed a sub-chronic study with a treatment of $100 \mathrm{mg} / \mathrm{kg}$ bw of dimethoate dissolved in the drinking water or in oil Of maize. The treatment time is 30 days. Two groups 
were defined: control group "receiving only the drinking water or corn oil" and the intoxicated group "receiving dimethoate dissolved in the drinking water or in the corn oil". Experimental procedures are also examined and approved by the internal ethical comittee for animal welfare.

\subsubsection{Procedure for the Treatment of Detoxification (Phyto-Processing)} After the period of intoxication and behavioral evaluation, rats (intoxicated by gavage or drinking water) received an extract by decoction of nettle. Indeed, $40 \mathrm{~g}$ of fresh leaves of Nettle have been roughly cut. After soaking in water for 24 hours, the whole is brought to boiling for 20 to 30 minutes under lid. After cooling the decoction under lid, filtering is carried out. This filtrate can be kept for only a few hours. A dose of $1 \mathrm{ml} / 100 \mathrm{mg}$ was administered orally to each of the intoxicated animals and this for duration of one month. The results of the treatment are finally compared with those of the control and intoxicated rats.

\subsection{Parameters Studied}

\subsubsection{Body Weight Measurements}

Signs of systemic toxicity such as convulsion, weakness and trembling were monitored. Weight is an important parameter in any experimental study because it is an indicator of physical health. The weight of each animal is monitored weekly with an electronic scale throughout the study.

\subsubsection{Behavioral Testing: Novel Object Recognition Memory}

\section{- Description of the device}

The object recognition memory test involves spontaneous exploration behavior in rodents, so it does not require food or water restriction or negative reinforcement of the animals. It is based on the spontaneous tendency of rats to preferentially explore a new object in relation to a familiar object. This device was used for the first time by [14].

This test takes place in a square open enclosure of $50 \times 50 \mathrm{~cm}^{2}(\mathrm{~L} \times 1)$, surrounded by four walls of $50 \mathrm{~cm}^{2}$ height. It is made of wood painted with black color, which gives the image of an open cube. The device is illuminated by a light source positioned at a height of one meter.

\section{- Experimental procedure}

At the beginning of the test, each animal is allowed to freely explore the device for 5 minutes in the absence of any object. Twenty-four hours later, the animal must explore two identical objects (A1 and A2) placed at the two adjacent corners of the device at $10 \mathrm{~cm}$ from the walls, for 5 minutes; this is the "acquisition" session. Exploration is only called when the rat has a nose directed less than one $\mathrm{cm}$ to the object, while nibbling and marking are not considered exploration. After a delay of 2 hours (for evaluation of short-term memory effect) or 24 hours (for long-term memory evaluation), the rat is placed again in the device, but this time, one of the two identical objects is replaced by another entirely different $B$ ). The animal is allowed to explore the two different objects for 5 minutes. The two sets of objects used were in dup- 
licate. The floor and objects are rinsed with $10 \%$ ethanol to remove any trace left by the animal in the device.

\section{- Parameters taken into account}

When the memory of the animal is not altered, it will explore the new object more than the old one, since it has memorized it. On the other hand, when the memory is defective, it will give more exploration time to the old object or it will explore both in an identical way. To evaluate the state of the memory, we calculated an index of recognition according to the following equation: Recognition index $=$ time spent exploring the object B / Sigma time spent exploring object A and B [14].

\subsection{Statistical Analysis}

We performed the statistical analyzes using the SPSS 20.0 software. Parametric ANOVA repeat tests and 1-factor ANOVA were used to compare the data series. When there was a difference between more than two batches, a further analysis was carried out with Tukey's post hoc test. The normality of distribution was first atested by the Kolmogorov-Smirnov test and homogeneity by the Levens test. The values of $\mathrm{p}<0.05$ are considered significant.

\subsection{Limitations of Study}

Although the research has reached its aims, there are some unavoidable limitations.

The main of them are expressed as follows:

- Lack of prior research studies on the topic.

- The environmental factor (temperature, light...) influences the behavior of the rats and must be taken into consideration.

- The sample size is an important feature of any study. The higher the number, the more reliable the results.

- If the mode of administration is by gavage, the rats should be handled with care to avoid throat irritation.

\section{Results}

\subsection{Macroscopic Observation}

Signs of systemic toxicity such as weight loss, resting quake, decreased food intake were observed in groups of rats poisoned compared to controls.

\subsection{Effect on Body Weight (Drinking Water)}

In males rats: sub-chronic intoxication with dimethoate for four weeks induces a progressive decrease in body weight in treated rats groups, unlike control rats Figure 1. The Friedman test followed by the Bonferroni post-hoc test shows that the differences observed are highly significant between the two study groups $(\mathrm{p}<0.001)$.

In female rats: A decrease in body weight was also observed in the group of 


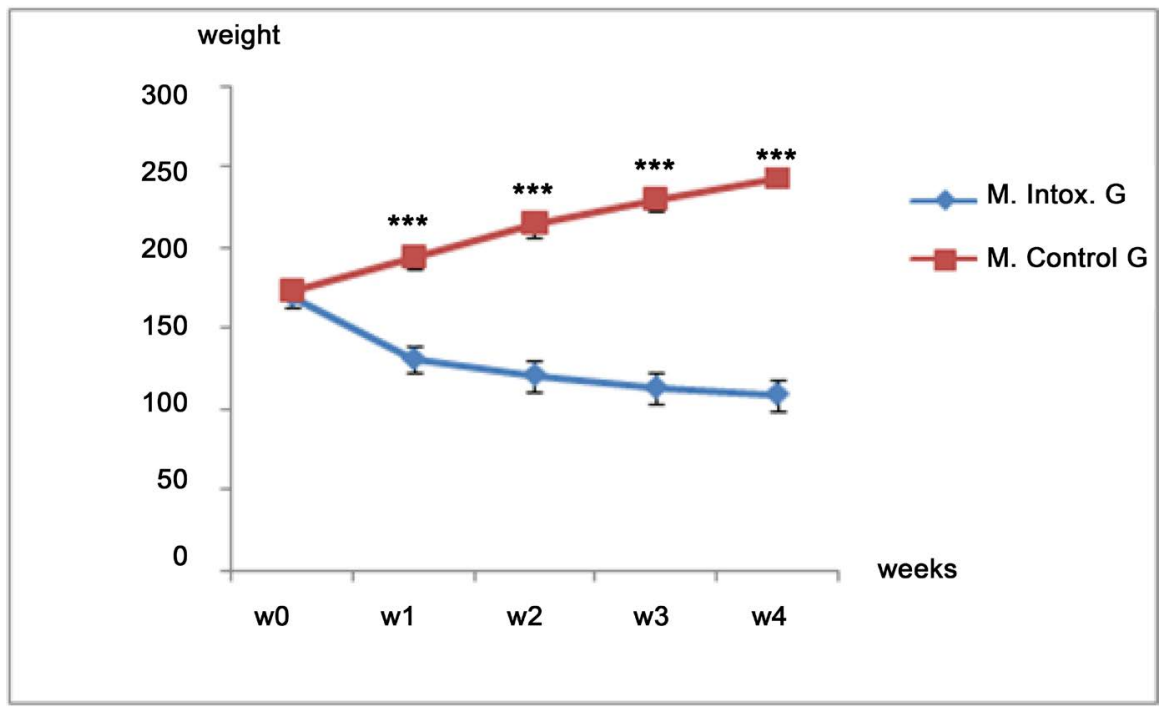

Figure 1. Effect of dimethoate on body weight in male rats Number of average errors \pm mean standard error (SEM). ${ }^{* *} \mathrm{p}<0.001$, comparison between intoxicated groups and controls.

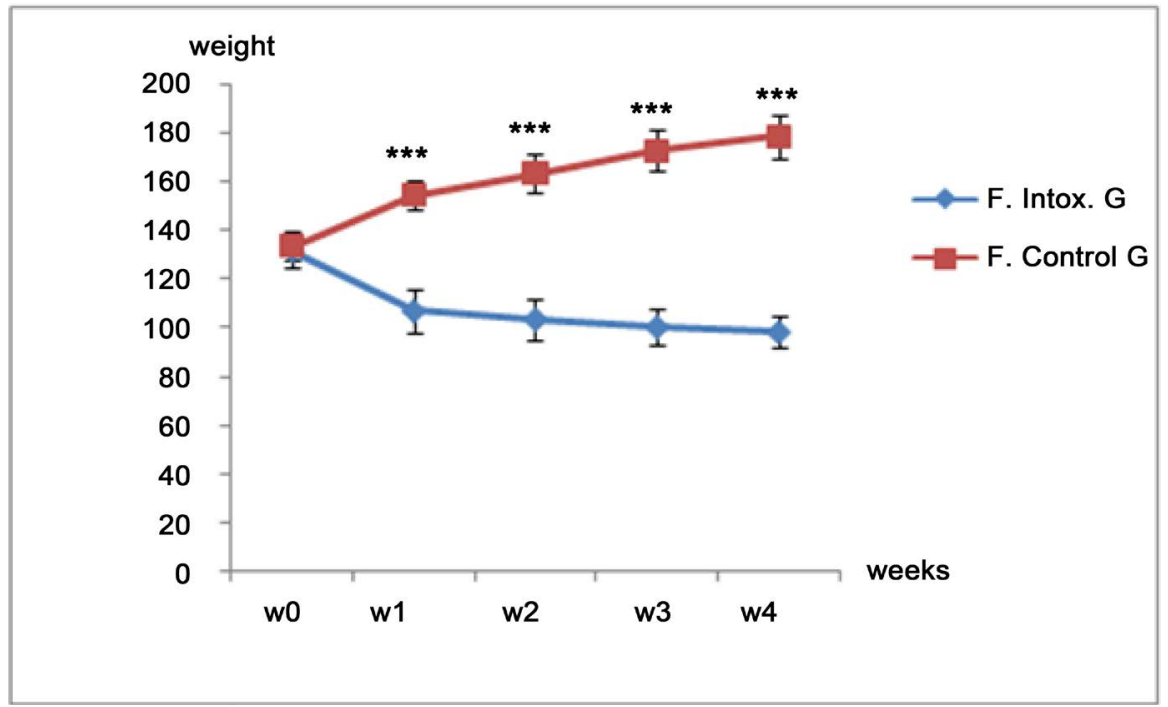

Figure 2. Effect of dimethoate on body weight in female rats Number of average errors \pm mean standard error (SEM). ${ }^{* * *} \mathrm{p}<0.001$, comparison between intoxicated groups and controls.

rats intoxicated during the study Figure 2. The Friedman test followed by the Bonferroni post-hoc test shows that this decrease is very highly significant $(\mathrm{p}<$ $0.001)$.

\subsection{Effect on Body Weight (Gavage)}

In males: Body weight remained steady throughout the study period in intoxicated rats, while it increased steadily in control rats Figure 3. The differences observed between the two study groups are highly significant $(\mathrm{p}<0.001)$.

In females: An increase in body weight was observed in female control rats 
compared with those poisoned by dimethoate gavage. The statistical analysis also showed a highly significant difference between the two study groups $(\mathrm{p}<0.001)$ Figure 4.

\subsection{Evaluation of Memory Functions}

\subsubsection{Effect on Short Term Memory Recognition (STM): Case of Gavage} In male rats: Figure 5 shows a decrease in the short-term recognition index. This index is below the recognition threshold in rats intoxicated with Dimethoate ( $\mathrm{IR}=40 \%$ ). This decrease is highly significant $\mathrm{p}<0.001$.

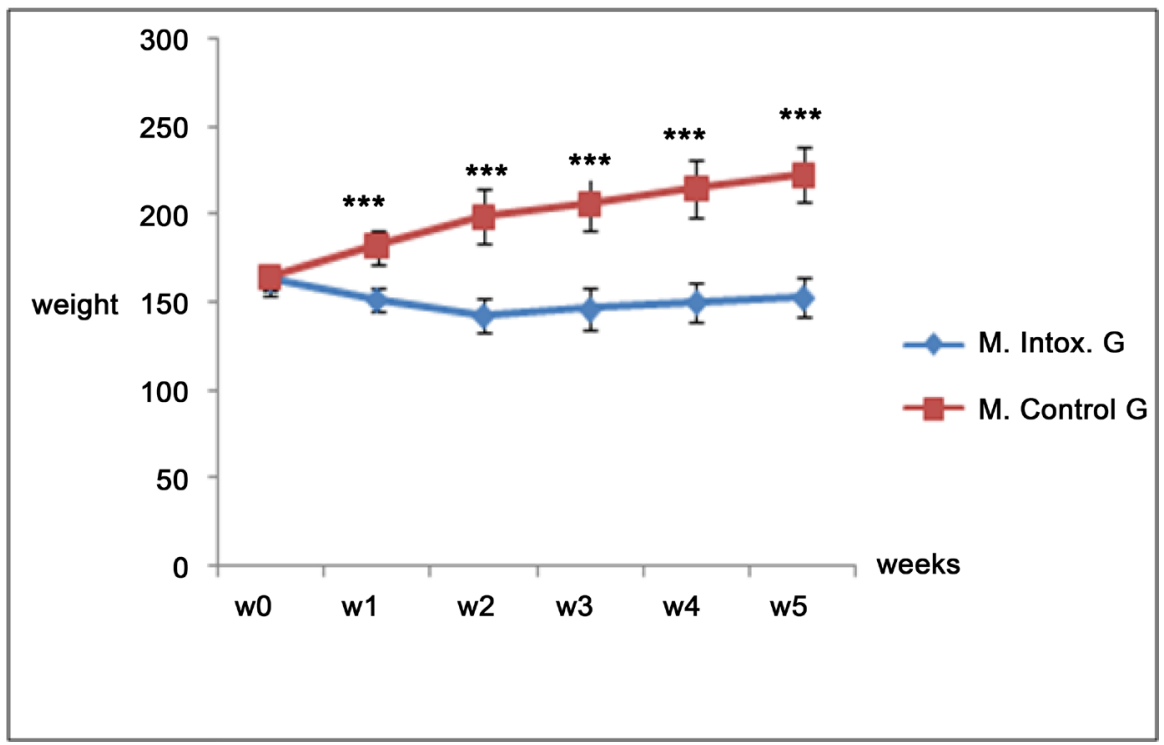

Figure 3. Effect of dimethoate on body weight in male rats Number of average errors \pm mean standard error (SEM). ${ }^{* *} \mathrm{p}<0.001$, comparison between intoxicated groups and controls.

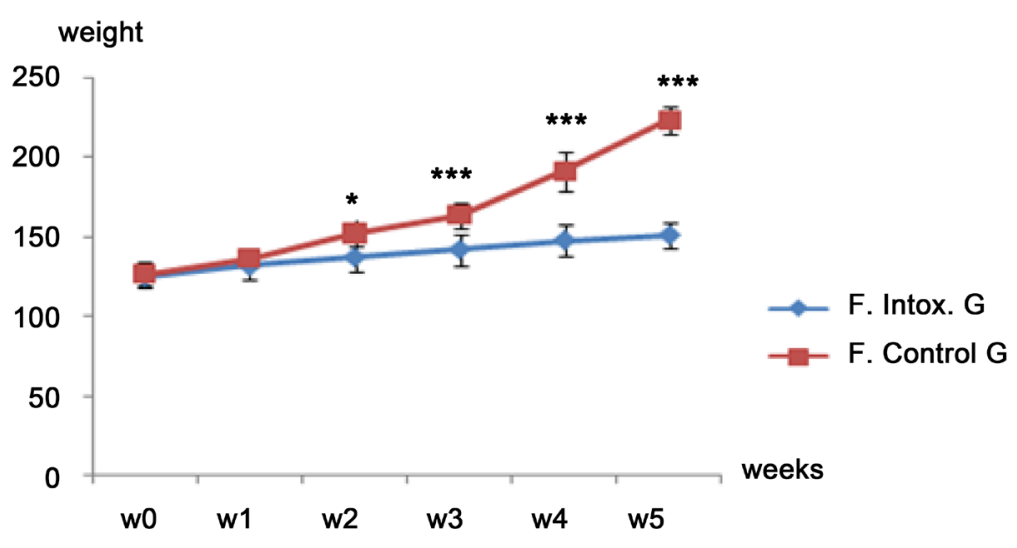

Figure 4. Effect of dimethoate on body weight in female rats Number of average errors \pm mean standard error (SEM). ${ }^{\star} \mathrm{p}<0.05,{ }^{* * *} \mathrm{p}<0.001$, comparison between intoxicated groups and control groups. 


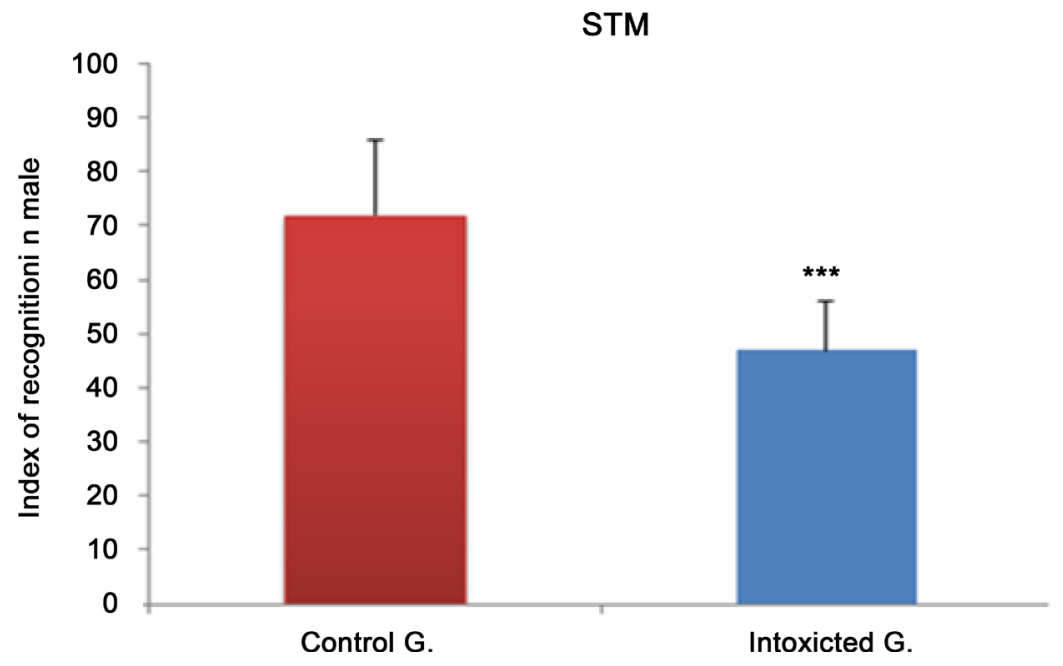

Figure 5. Effect of Dimethoate Exposure on Object Recognition STM in Male Rats Recognition index expressed on average \pm mean standard error (SEM). ${ }^{* *} \mathrm{p}<0.001$, comparison between intoxicated groups and controls.

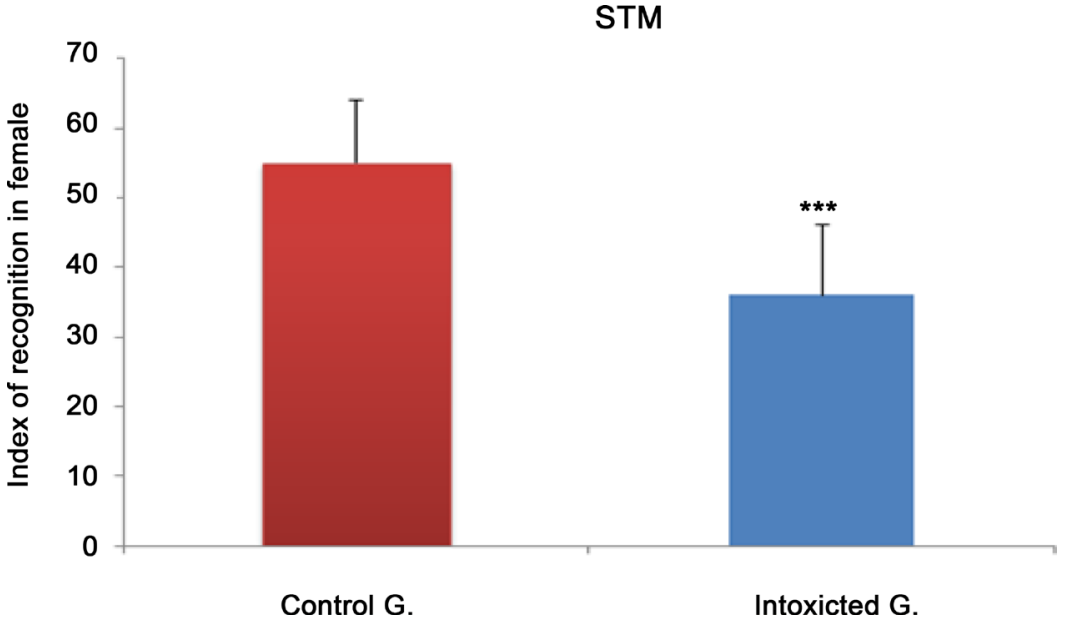

Figure 6. Effect of Dimethoate Exposure on Object Recognition STM in Female Rats Recognition index expressed on average \pm mean standard error $(\mathrm{SEM}) .{ }^{* *} \mathrm{p}<0.001$, comparison between intoxicated groups and controls.

In female rats: Dimethoate poisoning alters the short-term recognition memory in female rats. The expressed IR is highly significant between the two groups studied $\mathrm{p}<0.001$, either $43 \%$ to poisoned Figure 6 .

\subsubsection{Effects on STM Recognition: Drinking Water Case}

In male rats: Dimethoate poisoning in drinking water induces an alteration of (STM) in rats. Indeed, the index of recognition is highly reduced in intoxicated rats. $\mathrm{P}<0.001$, compared to controls in Figure 7.

In female rats: There was also a highly significant reduction in the index of recognition in Dimethoate addicts $\mathrm{p}<0.001$, compared with controls in Figure 8.

3.4.3. Effects on Long Term Memory Recognition (LTM): Case of Gavage In male rats: There was a significant decrease in long-term RI in rats treated with 


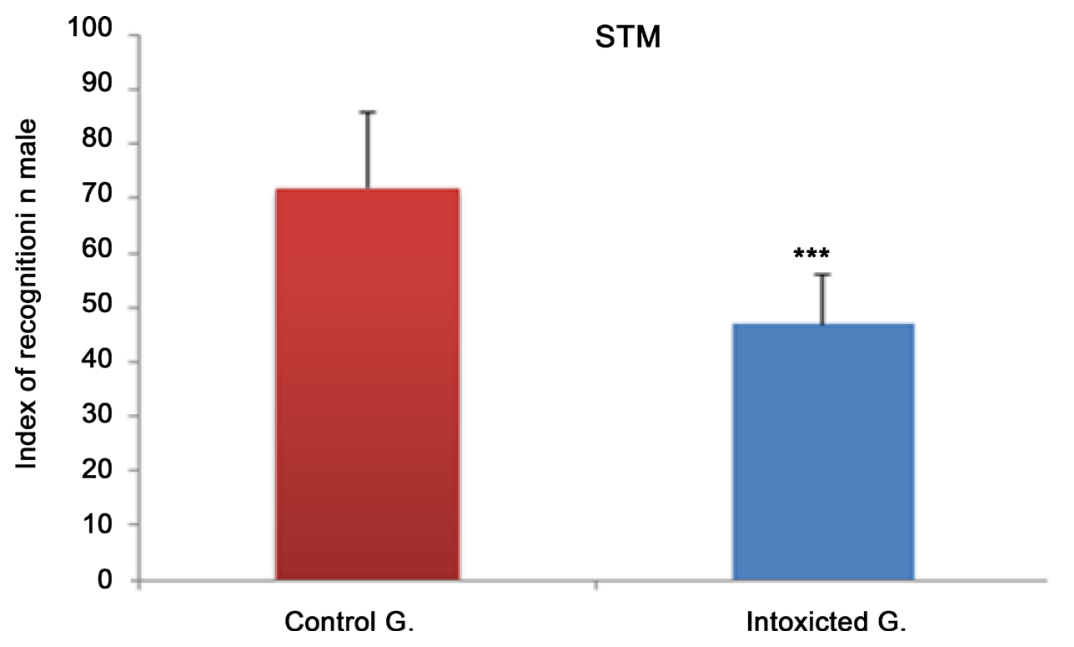

Figure 7. Effect of Dimethoate Exposure on Object Recognition STM In male rats Recognition index expressed on average \pm mean standard error (SEM). ${ }^{\star * *} \mathrm{p}<0.001$, comparison between intoxicated groups and controls.

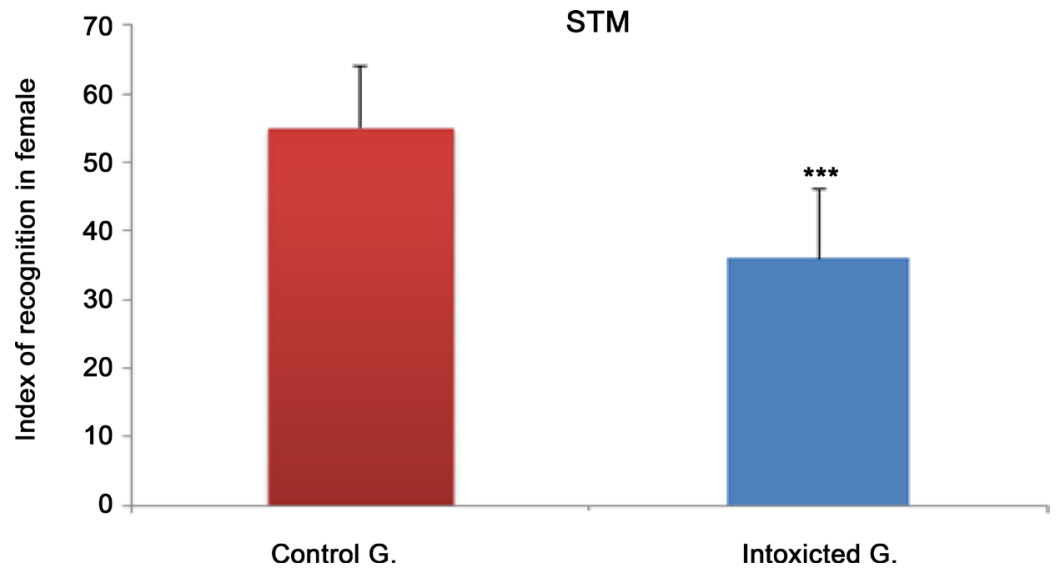

Figure 8. Effect of Dimethoate Exposure on Object Recognition STM in Female Rats Recognition index expressed on average \pm mean standard error $(\mathrm{SEM}) .{ }^{* *} \mathrm{p}<0.001$, comparison between intoxicated groups and controls.

Dimethoate gavage compared to controls, even though this index was above the $50 \%$ recognition threshold. The difference revealed is very statistically significant $\mathrm{p}<0.01$, Figure 9 .

In female rats: the long-term RI of $54 \%$ in intoxicated females did not differ significantly with controls $\mathrm{p}>0.05$ Figure 10 .

\subsubsection{Effects on Long Term Memory Recognition (LTM): Case of Gavage}

In male rats: As shown in Figure 11, RI is above the recognition threshold in rats treated with Dimethoate. However, this index differs significantly from that obtained by the control rats $\mathrm{p}<0.05$.

In female rats: It is also observed that the index of recognition is above the threshold of recognition of the objects in the rats intoxicated with Dimethoate, even if this index differs very significantly from that of the controls $p<0.01$, Figure 12. 


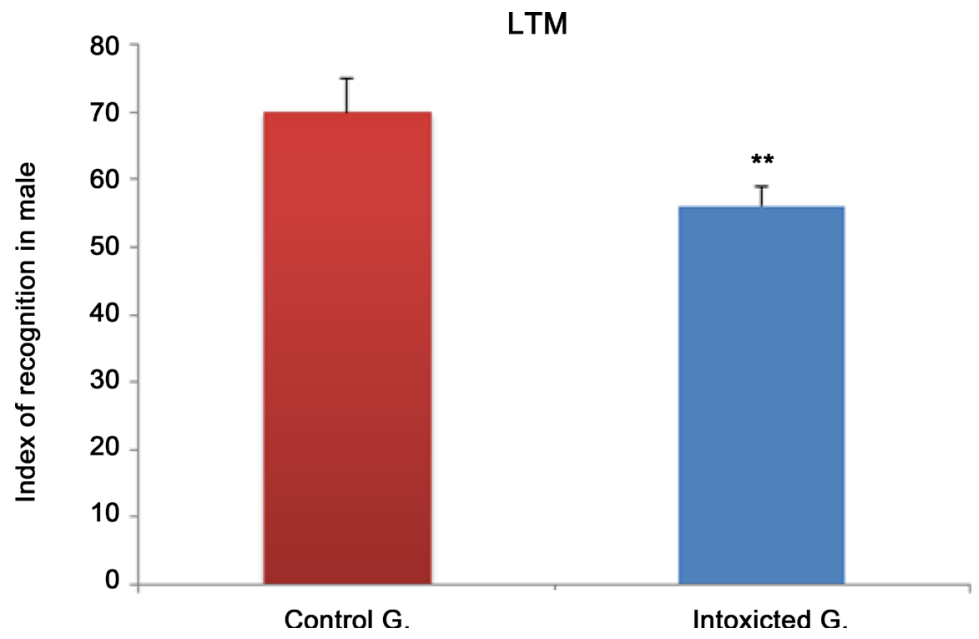

Figure 9. Effect of Dimethoate Exposure on Object Recognition LTM in Male Rats Recognition index expressed on average \pm mean standard error (SEM). ${ }^{\star *} \mathrm{p}<0.01$, comparison between intoxicated groups and controls.

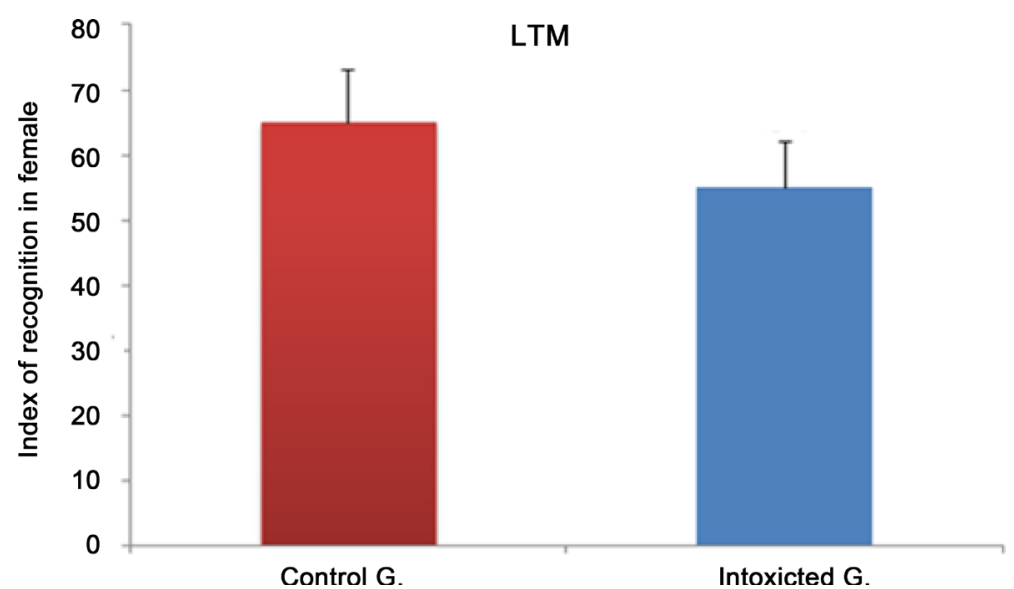

Figure 10. Effect of Dimethoate Exposure on LTM Recognition Objects in female rats Recognition index expressed as mean \pm mean standard error (SEM).

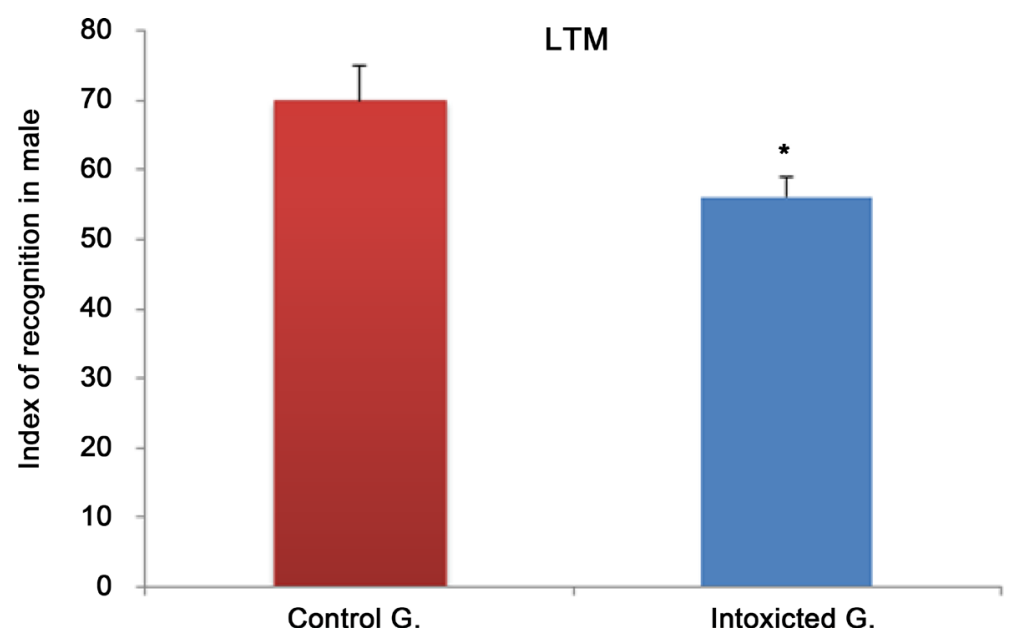

Figure 11. Effect of Dimethoate Exposure on LTM Recognition Objects in male rats Discrimination index expressed as average \pm mean standard error (SEM). ${ }^{*} \mathrm{p}<0.05$, comparison between intoxicated and control groups. 


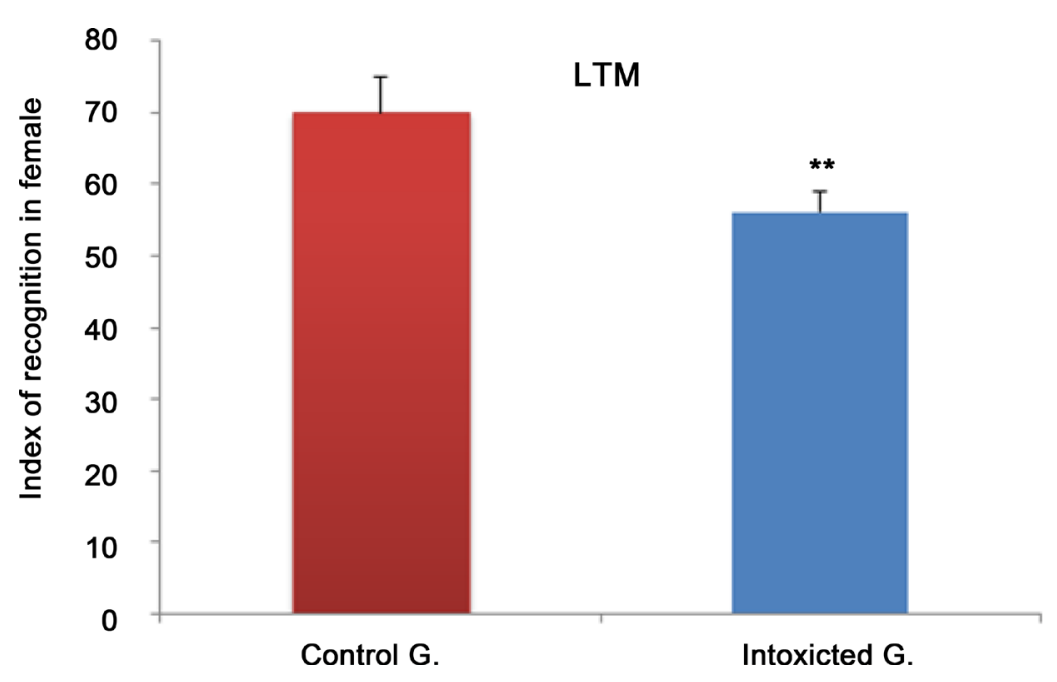

Figure 12. Effect of Dimethoate Exposure on LTM Recognition of Objects in female rats Discrimination index expressed as average \pm mean standard error $(\mathrm{SEM}) .{ }^{* *} \mathrm{p}<0.01$, comparison between intoxicated groups and controls.

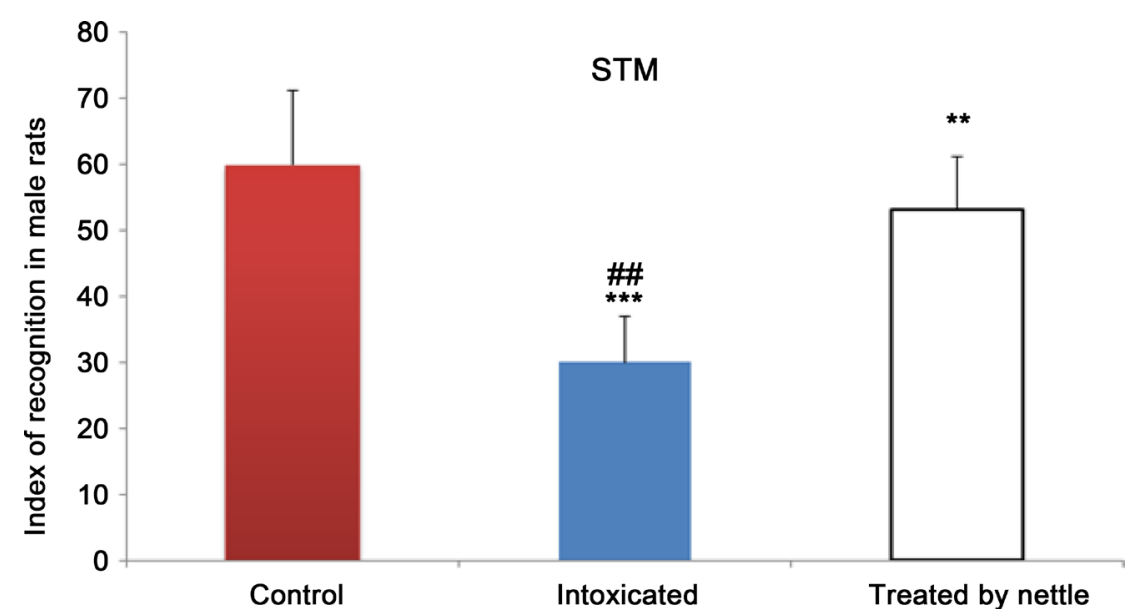

Figure 13. Effect of Urtica Dioica Medicinal Plant Treatment on Short-term Recognition Memory (STM) in Male Rats Recognition\% expressed as average \pm mean standard error (SEM). ${ }^{* * *} \mathrm{p}<0.001,{ }^{* *} \mathrm{p}<0.01$, comparison between the 3 groups treated; $\#$ \# $<0.01$, comparison between the dimethoate addicted group and plant-treated group (1-factor ANOVA/Tukey post-hoc analysis.

\subsection{Effects of Chelation Treatment on Memory Functions}

\subsubsection{Effects of Nettle Plant on STM Recognition: Drinking Water Case}

In male rats: Recognition STM is highly altered in rats treated with Dimethoate, the recognition index is $40 \%$ below the recognition threshold with a highly significant difference from that of the control rats $\mathrm{p}<0.001$. However, treatment with the medicinal plant Nettle Dioica has led to an improvement in this index, which has increased from $40 \%$ to $53 \%$, with a very significant difference $\mathrm{p}<0.01$, Figure 13.

In females: Observations similar to that of males were made. As shown in Figure 14, the recognition index is $35 \%$, which differs significantly from that of 
the controls $\mathrm{p}<0.001$. In contrast, treatment with the plant significantly increased this index to $51 \% \mathrm{p}<0.05$.

\subsubsection{Effects of Nettle Plant on Recognition LTM: Drinking Water Case}

In male rats: As shown in Figure 15, it is observed that the LTM of Recognition is weakly impaired with a $51 \%$ recognition in dimethoate $\mathrm{p}<0.05$, compared to controls. Treatment with the Nettle Dioica plant was able to slightly improve this index.

In females: The LTM index is very significantly decreased in Dimethoate addicts $\mathrm{p}<0.01$. However, it was possible to show a slight increase in this index after treatment with the plant Nettle dioica, this difference is not significant $\mathrm{p}<$ 0.05 (Figure 16).

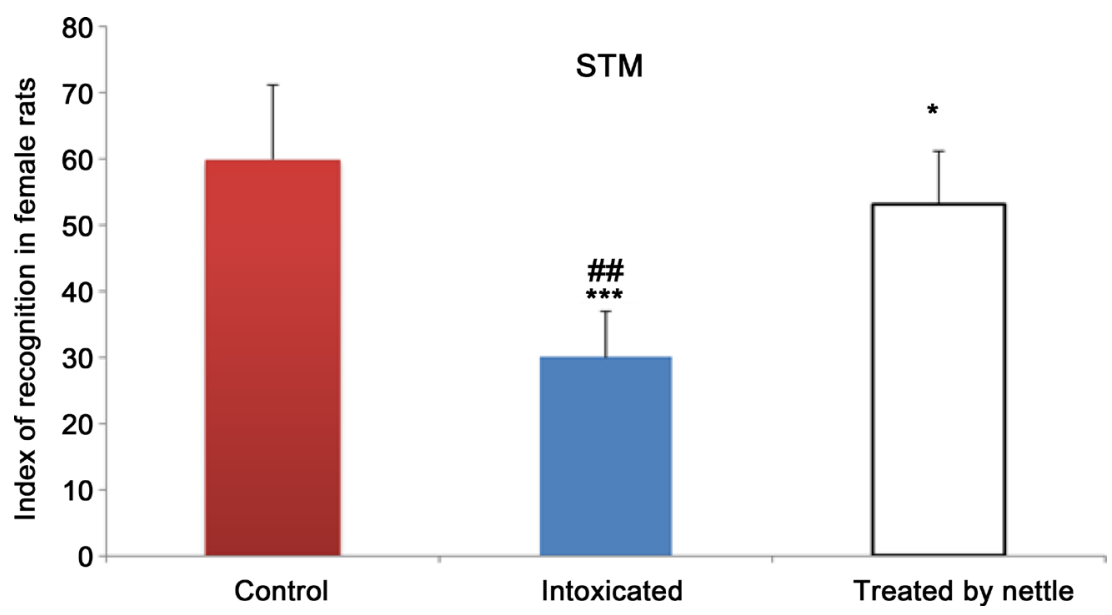

Figure 14. Effect of treatment by the medicinal plant Urtica Dioica on the short-term recognition memory (STM) in female rats Recognition\% expressed as average \pm mean standard error (SEM). ${ }^{* * *} \mathrm{p}<0.001,{ }^{*} \mathrm{p}<0.05$, comparison between the 3 treated groups; $\#$ \# $<0.01$, comparison between the dimethoate addicted group and plant-treated group (1-factor ANOVA/Tukey post-hoc analysis.

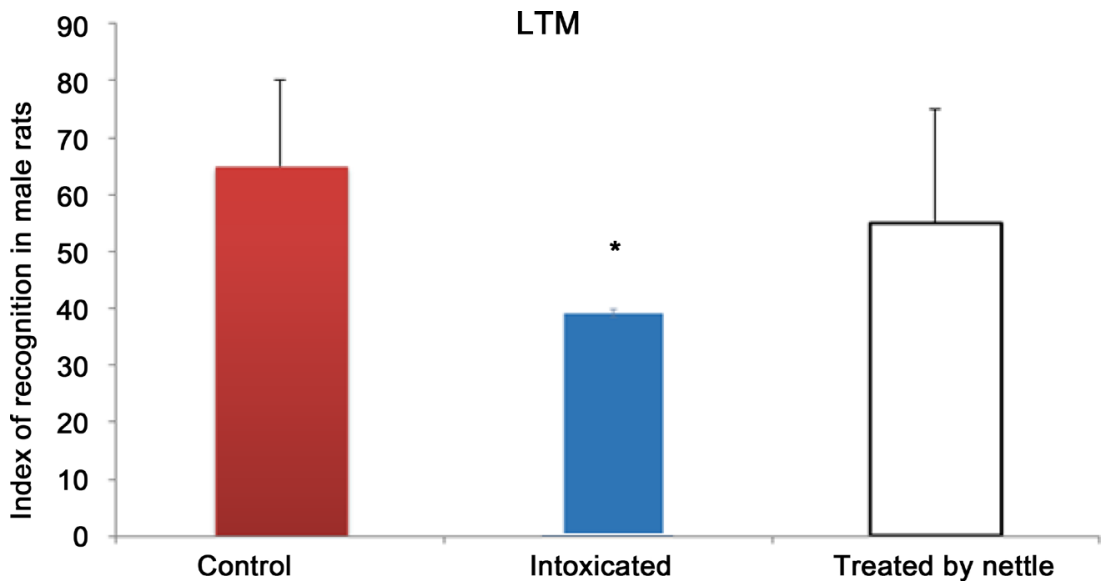

Figure 15. Effect of the Urtica Dioica Medicinal Plant Treatment on Long-Term Recognition Memory (LTM) in Male Rats Recognition\% expressed as average \pm mean standard error (SEM). ${ }^{*} \mathrm{p}<0.05$ comparison between the 3 groups treated. 


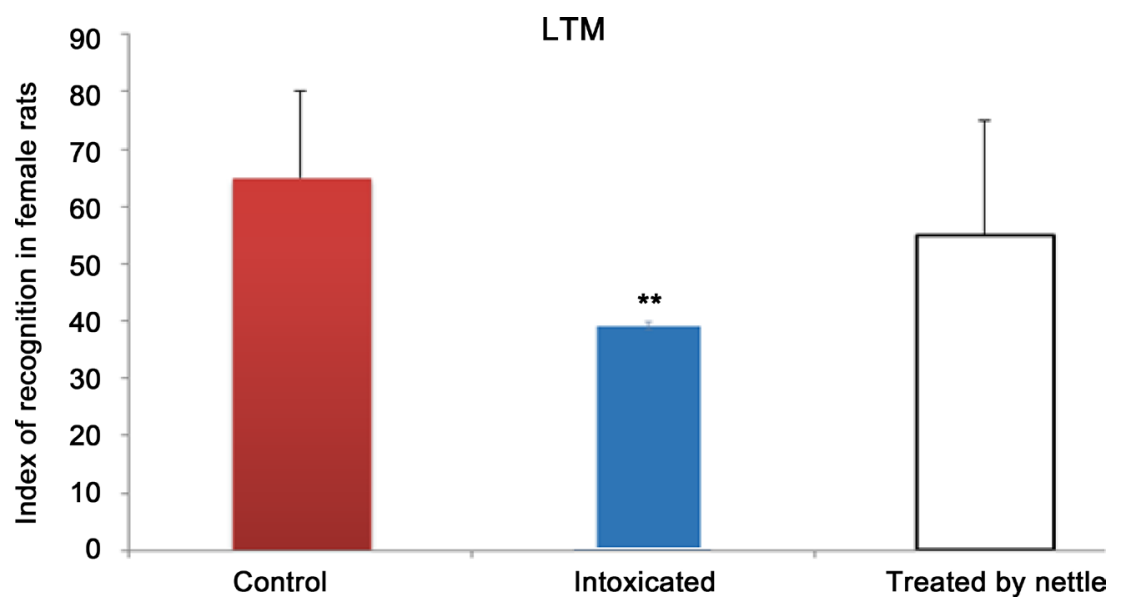

Figure 16. Effect of Urtica Dioica medicinal plant on long-term recognition memory (LTM) in female rats Recognition\% expressed as average \pm mean standard error (SEM). ${ }^{* *} \mathrm{p}<0.01$, comparison between the 3 groups treated (ANOVA with 1 factor/Post-hoc analysis of Tukey.

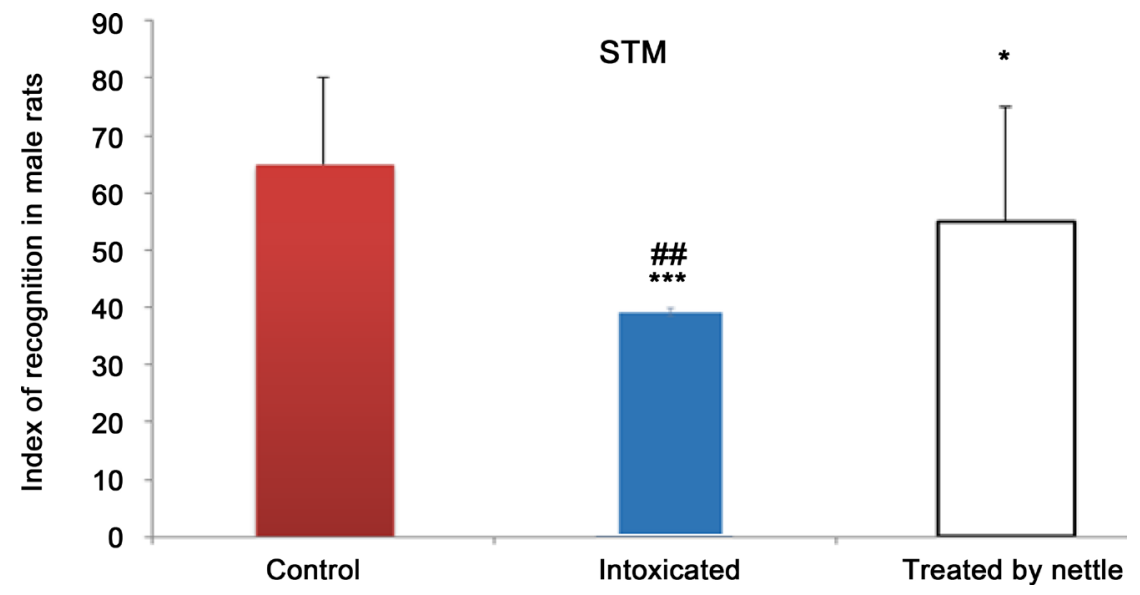

Figure 17. Effect of Urtica Dioica Medicinal Plant Treatment on Short-term Recognition Memory (STM) in Male Rats Recognition\% expressed as average \pm mean standard error (SEM). ${ }^{* *} \mathrm{p}<0.001,{ }^{*} \mathrm{p}<0.05$, comparison between the 3 treated groups; \#\#p $<0.01$, comparison between the dimethoate addicted group and plant-treated group (1-factor ANOVA/Tukey post-hoc analysis.

\subsubsection{Effects of the Nettle Plant on the STM of Recognition: Case of Gavage} In male rats: In the case of gavage intoxication, it was demonstrated that the recognition STM was very much reduced (37\%), compared to controls $\mathrm{p}<0.001$.

Treatment with the Nettle Dioica plant resulted in an improvement in this index, which rose from 37\% to $60 \%$ in Figure 17.

In females: As shown in Figure 18, poisoning also induced a high alteration of STM recognition with $40 \%$ index versus $70 \%$ in $\mathrm{p}<0.001$ controls. On the other hand, the treatment with the plant caused an improvement of this index to $59 \%$ $\mathrm{p}<0.001$.

\subsubsection{Effects of the Plant Nettle on the Recognition LTM: Case of Gavage} In male rats: Recovery LTM that was slightly impaired after intoxication was 
slightly improved after treatment with nettle plant $\mathrm{p}<0.001$ Figure 19.

In females: As shown in Figure 20, the LTM index of recognition was not sig-

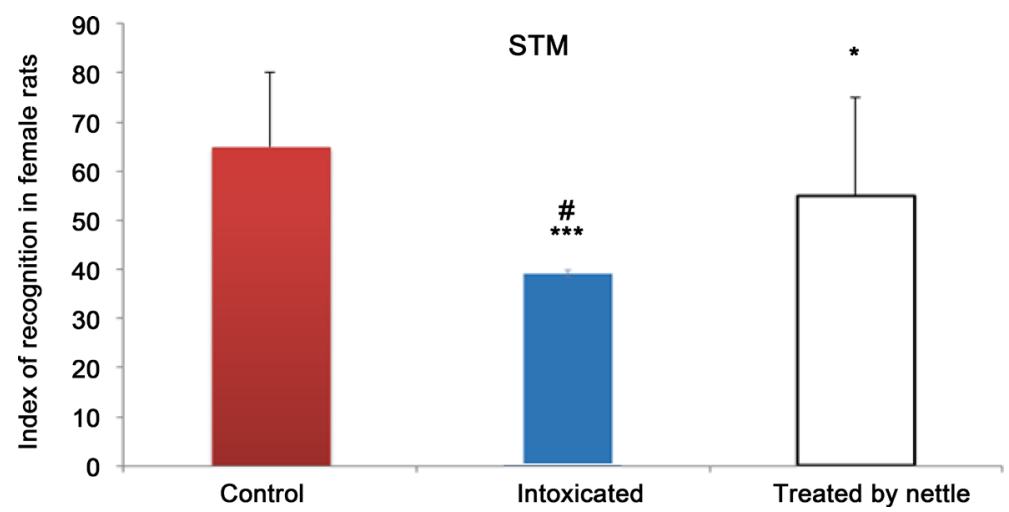

Figure 18. Effect of Urtica Dioica Medicinal Plant Treatment on Short-term Recognition Memory (STM) in Female Rats Recognition\% expressed as average \pm mean standard error (SEM). ${ }^{* *} \mathrm{p}<0.001,{ }^{*} \mathrm{p}<0.05$, comparison between the 3 treated groups; $\# \mathrm{P}<0.05$, comparison between the dimethoate poisoning group and plant-treated group (1-factor ANOVA/Tukey post-hoc analysis.

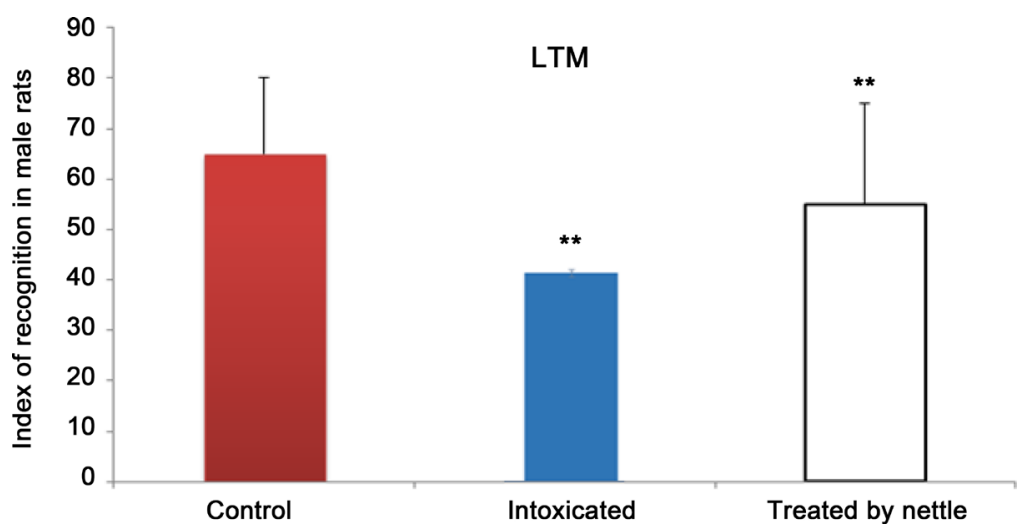

Figure 19. Effect of Urtica Dioica Medicinal Plant Treatment on Long-Term Recognition Memory (LTM) in Male Rats Recognition\% expressed as average \pm mean standard error (SEM). ${ }^{* *} \mathrm{p}<0.01$, comparison between the 3 treatment groups (1-factor ANOVA/Tukey post-hoc analysis).

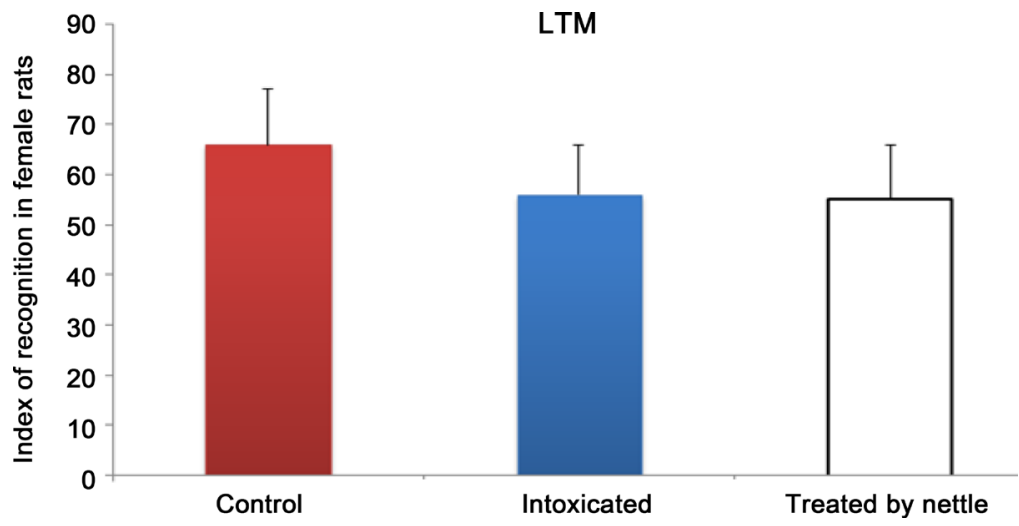

Figure 20. Effect of Urtica Dioica medicinal plant on memory Long-term recognition (LTM) in female rats. Recognition\% expressed as average \pm mean standard error (SEM). 
nificantly altered (54\%) in intoxicated rats, compared to controls $\mathrm{p}<0.05$. However, treatment with the Nettle plant allowed a small increase in this index without significant effect $\mathrm{p}<0.05$.

\section{Discussion}

\subsection{Effect of Dimethoate on Body Weight}

The effect of the diméthoate on the physical weight gain for both modes of administration behaves appreciably in a different way. Indeed, in the case of the poisoning with diméthoate in drinking water, we observe a highly significant decrease in weight depending on the duration of the treatment for both rats' sexes, as shown in Figure 1 and Figure 2. To the best of our knowledge, there have been no previous studies of this kind on the animal model. However these results indicate the significant impact of the diméthoate on the health of the agricultural populations living in the polluted middle. On the other hand, observations made in groups of rats exposed to dimethoate gavage show a slight decrease in body weight for both sexes males and females, as shown in Figure 3 and Figure 4. Our results are in line with the works of Jallouli on mice poisoned by the diméthoate [15].

Another study of the developmental toxicity in Malathion also demonstrates a low physical weight gain for young rats to the (GD 6-PND 45) stage [16]. From the physio-pathological point of view, the low physical weight gain of the exposed groups could be attributed to the effect of overexpression of the ACh molecules which increases the gastric motility and decreases the intestinal absorption [17]. Indeed, the parasympathetic nervous system stimulates the processes of digestion, through the NT ACh. However, the excess of this NT due to the inhibition of AChE by the OP could be the cause of the dysfunction of this process [18].

\subsection{Effect of Dimethoate on Memory Functions}

The recognition memory capabilities of rats intoxicated with Dimethoate were highlighted by the NOR (Novel Object) recognition memory test. This methodology allowed to link chronic exposure to OPs insecticides and memory impairment which is a serious health problem for the general population. In this work, short and long-term types of memory have been studied, both of which are very much affected in Alzheimer's disease [19].

The test is based on the spontaneous tendency of rodents to explore a new object in relation to another already seen. This cognitive test, evaluating the ability to recognize a previous stimulus, is a fundamental study of human amnesia by animal model [20]. Indeed, the memory of recognition rests on the ability to judge whether we have already encountered any stimulus, in fact visual (face, object, place...).

The results of our study reveal that the sub-chronic exposure to Dimethoate induces a significant alteration of the recognition memory of the objects. 
For STM short-term memory: In the case of rats poisoned by drinking-water, the recognition index was significantly decreased, with both sexes with a slightly pronounced effect in females: Figure 5 and Figure 6. The same observations are made in rats intoxicated by gavage. But this impact is more important when the intoxication is made by the drinking water: Figure 7 and Figure 8. Indeed, this index is below the recognition threshold of the objects, that is to say of $50 \%$ in the rats poisoned compared to the controls. This OP would therefore have disrupted the process of short-term memory formation. Our results are in agreement with a previous study which showed that Dimethoate poisoning produces an alteration of memory functions controlled by the hippocampus and the striatum [21].

To evoke hypotheses concerning the mechanism of action of alteration of memory, it is useful to know the cerebral structures considered as support for this cognitive function. Indeed, the NOR test model is influenced by hippocampal and cortical lesions [22] [23]. It is widely demonstrated that in rats and large apes, parahippocampal regions including the perirhinal cortex play a crucial role in the process of object recognition memory [24], i.e. their ability to evaluate a stimulus already encountered as a factor of familiarity based on the integrity of the medial temporal lobe [25]. This cerebral structure plays an important role in the formation of recognition memory. Its lesion leads to impaired performance [26]. A previous study has shown that exposure to subtoxic doses of Malathion induces a very significant inhibition of AChE in the hippocampus and associated regions [16]. The hippocampal system is rich in the cholinergic system, which has a central role in the encoding and consolidation of the new stimulus. This process therefore makes it possible to integrate and reorganize an already formed memory. By this means, in rodents, when a stimulus is previously experienced and reactivated, the hippocampus permits discrimination between the familiar and the new with a spontaneous and natural tendency to interact more with novelty [27]. Dysfunction in the OP induced cholinergic system in the hippocampus and/or perirhinal cortex may be suggested as a cause of alteration of short-term recognition memory. Indeed, the perirhinal cortex represents the main cerebral site of transit of information of environmental origin such as visual, olfactory and somatosensory stimuli, through which the hippocampus receives its "inputs" to form the memory [28].

For the long-term LTM recognition memory, our results also support a difference in the recognition index in the evaluation of the long-term recognition memory between the treated and control groups for the two forms of exposure, Even if this index turns out to be above the recognition threshold, as compared with the short-term recognition memory Figures 9-12. This implies that shortterm recognition memory is more vulnerable to exposure to dimethoate than to long-term memory. Similar results have been demonstrated in a previous study which showed that malathion-exposed rats have a short-term memory disrupted compared to long-term recognition memory [16]. It could be suggested that 
long-term recognition memory processes involve various components, such as subcortical and cortical structures. However, the sex effect that depends on the effect of dimethoate on recognition memory functions remains to be discussed. Indeed, the ability to recognize objects could be altered in both male rats and females exposed to Dimethoate. A developmental study showed that when the period of exposure to chlorpyrifos (CPF) occurs at the end of gestation (GD 17 20 ), only female mice with altered reference and working spatial memory. In this case, the muscarinic cholinergic system seems to be one of the systems whose functioning is modified or altered [29] [30]. On the other hand, if the period of exposure to CPF occurs postnatally, during the first days of life (PND $1-4$ ), it is only the male mice that have spatial memory problems [31]. This implies that in order to better understand the sex-effect of dimethoate, exposure studies on different stages of development should be undertaken.

\subsection{Effect of Nettle on the Functions of Memory}

Although we have studied the effects of dimethoate intoxication in rats, we have tested the therapeutic effects of a medicinal plant, Nettle, which has antioxidant properties. In order to better support its properties, it is desirable to evoke the pro-oxidizing and proinflammatory effects induced by OPs in general and Dimethoate in particular. Most authors agree that chronic or acute exposure induces oxidative and proinflammatory stress effects in animals [4] [31] [32] [33] [34] [35].

In addition, dimethoate intoxication has been shown to cause cellular alterations and oxidative stress, leading to lipid peroxidation and the generation of free radicals [4] [36] [37]. In this study it was demonstrated that Nettle treatment resulted in a remarkable improvement in short-term memory recognition capacity, which was strongly altered by dimethoate. Indeed, antioxidants constitute the defense system that limits the toxicity associated with free radicals [38]. In addition, a dietary intake rich in antioxidant products has shown protective effects against oxidative stress [38] [39], this has been demonstrated for vitamin $\mathrm{E}$ [40] [41] and for Selenium [39].

These results suggest that nettle treatment has a positive effect by eliminating free radicals associated with exposure to Dimethoate. In addition, it would be appropriate to investigate the effects of dimethoate on the serotonergic system and on the catecholamines involved in the regulation of memory performance [42]. These systems have been disturbed during intoxication with CPF [43] [44] [45] [46] and methyl parathion [47].

\section{Conclusions}

Agriculture makes extensive use of pesticides and phytosanitary products. By destroying pests and weeds, these substances improve crops and guarantee the availability, quality, reliability and prices of agricultural products for the benefit of farmers and consumers. 
Used improperly, pesticides constitute nevertheless a danger, because most can damage the health and the environment.

In this study, we have demonstrated that poisoning by dimethoate alters the short-term memory functions of wistar rats.

We have also tested the effect of nettle as a chelating treatment trial. An improvement in short-term memory was obtained.

\section{References}

[1] Carson, R. $(1963,1994)$ Silent Spring. Houghton Mifflin, Boston, Massachusetts.

[2] Costa, L.G. (2006) Current Issues in Organophosphate Toxicology. Clinica Chimica Acta, 366, 1-13. https://doi.org/10.1016/j.cca.2005.10.008

[3] Halliwell, B. (2006) Reactive Species and Antioxidants. Redox Biology Is a Fundamental Theme of Aerobic Life. Plant Physiology, 141, 312-322.

https://doi.org/10.1104/pp.106.077073

[4] Yukti, S., Bashir, S., Irshad, M., Gupta, S.D. and Dogra, T.D. (2005) Effects of Acute Dimethoate Administration on Antioxidant Status of Liver and Brain of Experimental Rats. Toxicology, 206, 49-57. https://doi.org/10.1016/j.tox.2004.06.062

[5] Wichtl, M. and Anton, R. (2003) Plantes thérapeutiques, tradition, pratique officinale, science et thérapeutique. [Therapeutic Plants, Tradition, Officinal Practice, Science and Therapeutics.] 2nd Edition, Inter/Tec \& Doc Éditions, Paris, 587-589.

[6] Henri, C. (1997) Traité pratique et raisonné des plantes médicinales indigènes. [Practical and Rational Treaty of Native Medicinal Plants.] 3rd Edition, de l'Envol, Paris, $1251 \mathrm{p}$.

[7] Kataki, M.S., Murugamani, V., Rajkumari, A., Mehra, P.S., Awasthi, D. and Yadav, R.S. (2012) Antioxidant, Hepatoprotective, and Anthelmintic Activities of Methanol Extract of Urtica dioica L. Leaves. Pharmaceutical Crops, 3, 38-46. https://doi.org/10.2174/2210290601203010038

[8] Khare, V., Kushwaha, P., Verma, S., Gupta, A., Srivastava, S. and Rawat, A.K.S. (2012) Pharmacognostic Evaluation and Antioxidant Activity of Urtica dioica L. Chinese Medicine, 3, 128-135. https://doi.org/10.4236/cm.2012.33021

[9] Pourmorad, F., Hosseinimehr, S.J. and Shahabimajd, N. (2006) Antioxidant Activity, Phenol and Flavonoid Contents of Some Selected Iranian Medicinal Plants. African Journal of Biotechnology, 5, $1142-1145$.

[10] Gulcin, I., Kufrevioglu, O.I.., Oktay, M. and Buyukokuroglu, M.E. (2004) Antioxidant, Antimicrobial, Antiulcer and Analgesic Activities of Nettle (Urtica dioica L.). Journal of Ethnopharmacology, 90, 205-215. https://doi.org/10.1016/j.jep.2003.09.028

[11] Kanter, M., Coskun, O. and Budancamanak, M. (2005) Hepatoprotective Effects of Nigella sativa L and Urtica dioica L on Lipid Peroxidation, Antioxidant Enzyme Systems and Liver Enzymes in Carbon Tetrachloride-Treated Rats. World Journal of Gastroenterology, 11, 6684-6688. https://doi.org/10.3748/wjg.v11.i42.6684

[12] Sarni-Manchado, P. and Cheynier, V., Eds. (2006) Les polyphénols en agroalimentaire. [Polyphenols in Agroalimentary.] Techniques \& Documentation.

[13] Gallo, M.A. and Lawryk, N.J. (1991) Organic Phosphorus Pesticides. In: Hayes Jr., W.J. and Laws Jr., E.R., Eds., Handbook of Pesticide Toxicology, Vol. 2, Classes of Pesticides, Academic Press, San Diego, 917-1123.

[14] Ennaceur, A. and Delacour, J. (1988) A New One-Trial Test for Neurobiological 
Studies of Memory in Rats. 1: Behavioral Data. Behavioural Brain Research, 31, 47-59. https://doi.org/10.1016/0166-4328(88)90157-X

[15] Jallouli, M., El Bini Dhouib, I., Dhouib, H., Gharbi, N. and El Fazaa, S. (2015) Effects of Dimethoate in Male Mice Reproductive Parameters. Regulatory Toxicology and Pharmacology, 73, 853-858. https://doi.org/10.1016/j.yrtph.2015.10.010

[16] N'Go, P.K., Azzaoui, F.-Z., Soro, P.R., Samih, M., Ahami, A.O.T., Najimi, M. and Chigr, F. (2013) Developmental Effects of Malathion Exposure on Recognition Memory and Spatial Learning in Males Wistar Rats. JBBS, 3, 331-340. https://doi.org/10.4236/jbbs.2013.33033

[17] Jones, A.L. and Karalliedde, L. (2006) Davidson's Principles and Practice of Medicine. In: Boon, N.A., Colledge, N.R., Davidson, S.S. and Walker, B.R., Eds., 2nd Edition, Churchill Livingstone, Edinburgh, 203-226.

[18] Eskenazi, B., Bradman, A. and Castorina, R. (1999) Exposures of Children to Organophosphate Pesticides and Their Potential Adverse Health Effects. Environmental Health Perspectives, 107, 409. https://doi.org/10.1289/ehp.99107s3409

[19] Dibo-Cohen, C.M. (2006) Mémoire spatiale contextuelle et schizophrénie. [Contextual Spatial Memory and Schizophrenia.] Université Pierre et Marie Curie-Paris VI, Français.

[20] Baxter, M.G. (2009) Involvement of Medial Temporal Lobe Structures in Memory and Perception. Neuron, 61, 667-677. https://doi.org/10.1016/j.neuron.2009.02.007

[21] Mauricio, V.-H., Castillo, I., Díaz, C., Alés, I. and Rodríguez-Moreno, A. (2012) Dimethoate Accelerates the Extinction of Eyeblink Conditioning in Mice. Neurotoxicology, 33, 105-110. https://doi.org/10.1016/j.neuro.2011.12.003

[22] Buckmaster, C.A., Eichenbaum, H., Amaral, D.G., Suzuki, W.A. and Rapp, P.R. (2004) Entorhinal Cortex Lesions Disrupt the Relational Organization of Memory in Monkeys. Journal of Neuroscience, 24, 9811-9825. https://doi.org/10.1523/JNEUROSCI.1532-04.2004

[23] Clarke, B.O., Porter, N.A., Marriott, P.J. and Blackbeard, J.R. (2010) Investigating the Levels and Trends of Organochlorine Pesticides and Polychlorinated Biphenyl in Sewage Sludge. Environment International, 36, 323-329. https://doi.org/10.1016/j.envint.2010.01.004

[24] Aggleton, J.P., O’Mara, S.M., Vann, S.D., Wright, N.F., Tsanov, M. and Erichsen, J.T. (2010) Hippocampal-Anterior Thalamic Pathways for Memory: Uncovering a Network of Direct and Indirect Actions. European Journal of Neuroscience, 31, 2292-2307. https://doi.org/10.1111/j.1460-9568.2010.07251.x

[25] Hammond, B., Dudek, R., Lemen, J. and Nemeth, M. (2004) Results of a 13 Week Safety Assurance Study with Rats Fed Grain from Glyphosate Tolerant Corn. Food and Chemical Toxicology, 42, 1003-1014. https://doi.org/10.1016/j.fct.2004.02.013

[26] Albasser, M.M., Amin, E., Lin, T.-C.E., Iordanova, M.D. and Aggleton, J.P. (2012) Evidence That the Rat Hippocampus Has Contrasting Roles in Object Recognition Memory and Object Recency Memory. Behavioral Neuroscience, 126, 659. https://doi.org/10.1037/a0029754

[27] Antunes, M.S., Morey, K.J., Smith, J.J., Albrecht, K.D., Bowen, T.A., Zdunek, J.K., Troupe, J.F., Cuneo, M.J., Webb, C.T., Hellinga, H.W., et al. (2011) Programmable Ligand Detection System in Plants through a Synthetic Signal Transduction Pathway. PLoS One, 6, e16292. https://doi.org/10.1371/journal.pone.0016292

[28] Rosauro, C.J., Cammarota, M., Gruart, A., Izquierdo, I. and Delgado-García. J.M. (2010) Plastic Modifications Induced by Object Recognition Memory Processing. Proceedings of the National Academy of Sciences, 107, 2652-2657. 
https://doi.org/10.1073/pnas.0915059107

[29] Levin, D.T., Drivdahl, S.B., Momen, N. and Beck, M.R. (2002) False Predictions about the Detectability of Visual Changes: The Role of Beliefs about Attention, Memory, and the Continuity of Attended Objects in Causing Change Blindness Blindness. Consciousness and Cognition, 11, 507-527. https://doi.org/10.1016/S1053-8100(02)00020-X

[30] Jean-Baptiste, B., Quertemont, E., Tirelli, E. and Plumier, J.-C. (2010) Anxiety in Adult Female Mice Following Perinatal Exposure to Chlorpyrifos. Neurotoxicology and Teratology, 32, 234-239. https://doi.org/10.1016/j.ntt.2009.08.008

[31] Aldridge, J.E., Meyer, A., Seidler, F.J. and Slotkin, T.A. (2005) Alterations in Central Nervous System Serotonergic and Dopaminergic Synaptic Activity in Adulthood after Prenatal or Neonatal Chlorpyrifos Exposure. Environmental Health Perspectives, 113, 1027-1031. https://doi.org/10.1289/ehp.7968

[32] Maryam, A., Abdollahi, M., Kebryaeezadeh, A., Hosseini, R. and Sabzevari, O. (2003) Biochemical Evidence for Free Radicalinduced Lipid Peroxidation as a Mechanism for Subchronic Toxicity of Malathion in Blood and Liver of Rats. Human \& Experimental Toxicology, 22, 205-211. https://doi.org/10.1191/0960327103ht346oa

[33] Banks, C.N. and Lein, P.J. (2012) A Review of Experimental Evidence Linking Neurotoxic Organophosphorus Compounds and Inflammation. Neurotoxicology, 33, 575-584. https://doi.org/10.1016/j.neuro.2012.02.002

[34] Kathleen, R. and Xiong, S. (1997) Effect of Administration of Malathion for 14 Days on Macrophage Function and Mast Cell Degranulation. Toxicological Sciences, 37, 95-99. https://doi.org/10.1093/toxsci/37.1.95

[35] Singh, A.K. and Jiang, Y. (2003) Lipopolysaccharide (lps) Induced Activation of the Immune System in Control Rats and Rats Chronically Exposed to a Low Level of the Organothiophosphate Insecticide, Acephate. Toxicology and Industrial Health, 19, 93-108. https://doi.org/10.1191/0748233703th181oa

[36] Reuber, M.D. (1984) Carcinogenicity of Dimethoate. Environmental Research, 34, 193-211. https://doi.org/10.1016/0013-9351(84)90089-6

[37] Ferah, S. (2007) Histopathological Effects of Dimethoate on Testes of Rats. Bulletin of Environmental Contamination and Toxicology, 78, 479-484. https://doi.org/10.1007/s00128-007-9196-5

[38] Joël, P., Bonjean, K., Cayeux, K. and Defraigne, J.-O. (2002) Mécanismes physiologiques de la défense antioxydante. [Physiological Mechanisms of Antioxidant Defense.] Nutrition clinique and métabolisme, 16, 233-239. https://doi.org/10.1016/S0985-0562(02)00166-8

[39] Ben Amara, I., Soudani, N., Troudi, A., Bouaziz, H., Boudawara, T. and Zeghal, N. (2011) Antioxidant Effect of Vitamin E and Selenium on Hepatotoxicity Induced by Dimethoate in Female Adult Rats. Ecotoxicology and Environmental Safety, 74, 811-819. https://doi.org/10.1016/j.ecoenv.2010.11.007

[40] Schwenke, D.C. and Behr, S.R. (1998) Vitamin E Combined with Selenium Inhibits Atherosclerosis in Hypercholesterolemic Rabbits Independently of Effects on Plasma Cholesterol Concentrations. Circulation Research, 83, 366-377. https://doi.org/10.1161/01.RES.83.4.366

[41] Shireen, K.F., Pace, R.D., Mahboob, M. and Khan, A.T. (2008) Effects of Dietary Vitamin E, C and Soybean Oil Supplementation on Antioxidant Enzyme Activities in Liver and Muscles of Rats. Food and Chemical Toxicology, 46, 3290-3294. https://doi.org/10.1016/j.fct.2008.07.015 
[42] Ove, Ö.S., Eriksson, T.M., Elvander-Tottie, E., D’Addario, C., Ekström, J.C., Svenningsson, P., Meister, B., Kehr, J. and Stiedl, O. (2008) The Role of 5-ht 1a Receptors in Learning and Memory. Behavioural Brain Research, 195, 54-77. https://doi.org/10.1016/j.bbr.2008.02.023

[43] Aldridge, J.E., Seidler, F.J., Meyer, A., Thillai, I. and Slotkin, T.A. (2003) Serotonergic Systems Targeted by Developmental Exposure to Chlorpyrifos: Effects during Different Critical Periods. Environmental Health Perspectives, 111, 1736. https://doi.org/10.1289/ehp.6489

[44] Slotkin, T.A. (2002) Nicotine and the Adolescent Brain: Insights from an Animal Model. Neurotoxicology and Teratology, 24, 369-384. https://doi.org/10.1016/S0892-0362(02)00199-X

[45] Slotkin, T.A., Lassiter, T.L., Ryde, I.T., Wrench, N., Levin, E.D. and Seidler. F.J. (2009) Consumption of a High-Fat Diet in Adulthood Ameliorates the Effects of Neonatal Parathion Exposure on Acetylcholine Systems in Rat Brain Regions. Environmental Health Perspectives, 117, 916. https://doi.org/10.1289/ehp.0800459

[46] van Dam, P.S., Bravenboer, B., van Asbeck, B.S., Marx, J.J.M. and Gispen, W.H. (1999) High Rat Food Vitamin E Content Improves Nerve Function in Streptozotocin-Diabetic Rats. European Journal of Pharmacology, 376, 217-222. https://doi.org/10.1016/S0014-2999(99)00376-3

[47] Mohammed, M., Shireen, K.F., Atkinson, A. and Khan, A.T. (2001) Lipid Peroxidation and Antioxidant Enzyme Activity in Different Organs of Mice Exposed to Low Level of Mercury. Journal of Environmental Science and Health, Part B, 36, 687-697. https://doi.org/10.1081/PFC-100106195

Submit or recommend next manuscript to SCIRP and we will provide best service for you:

Accepting pre-submission inquiries through Email, Facebook, LinkedIn, Twitter, etc. A wide selection of journals (inclusive of 9 subjects, more than 200 journals)

Providing 24-hour high-quality service

User-friendly online submission system

Fair and swift peer-review system

Efficient typesetting and proofreading procedure

Display of the result of downloads and visits, as well as the number of cited articles

Maximum dissemination of your research work

Submit your manuscript at: http://papersubmission.scirp.org/

Or contact jbbs@scirp.org 